\title{
SEMINAL VESICULECTOMY IN BULLS
}

\section{SEMINAL BIOGHEMISTRY}

\author{
B. A. SHAH,* M. L. HOPWOOD AND L. G. FAULKNER \\ Departments of Biochemistry and Clinics and Surgery, \\ Colorado State University, Fort Collins, Colorado, U.S.A.
}

(Received 12th Fune 1967)

\begin{abstract}
Summary. Sperm-rich and pre-sperm ejaculates were collected from bulls before and after excision of the seminal vesicles, and the composition of the fluids was analysed. In the pre-sperm fraction, vesiculectomy did not alter $\mathrm{pH}$ or levels of chloride, nitrogen and free amino acids. There was little alkaline phosphatase activity in the pre-sperm fraction before surgery, and this low level was further decreased by vesiculectomy, as were fructose, citrate and potassium, while sodium concentration increased. In the sperm-rich fraction, the volume was reduced by vesiculectomy, as were levels of fructose, citrate, potassium and alkaline phosphatase activity. Chloride, glycerylphosphorylcholine and free amino acid levels increased after vesiculectomy. Sodium concentration and $\mathrm{pH}$ were unaltered.

The findings indicate that the vesicular glands contribute to the presperm fraction and more significantly to the sperm-rich portion of the ejaculate. The glands that secrete the bulk of the pre-sperm fraction also contribute to the sperm-rich fraction. This investigation clarifies the biochemical contributions of the seminal vesicles to the ejaculate. The glandular contributions to the pre-sperm fraction remain to be defined.
\end{abstract}

\section{INTRODUCTION}

Differences in the chemistry of bovine seminal plasma may be largely attributed to the function of the accessory glands, since these glands are the major sources of secretions that contribute to the fluid volume of semen. Sixty to $90 \%$ of the volume of a normal ejaculate comes from the accessory glands, of which the seminal vesicles contribute the largest portion.

The work reported here was performed to add to knowledge of the contribution of the seminal vesicles to the composition of semen.

\section{Semen collection}

\section{MATERIALS AND METHODS}

Semen was collected by artificial vagina from five Hereford bulls which were 1.5 years of age at the beginning of the study. Pre-sperm fractions were collected

* In partial fulfilment of requirements for the M.S. degree. Present address: Department of Dairy Science, Peshawar University, West Pakistan. 
according to procedures of Faulkner, Masken \& Hopwood (1964). Samples of pre-sperm and sperm-rich fractions from each bull were analysed before and after seminal vesiculectomy.

\section{Surgical procedure}

Two surgical approaches to the seminal vesicles were investigated. With either approach, food was withheld for $24 \mathrm{hr}$, and no water was given for 12 $\mathrm{hr}$ before the operation. Surgical sites were clipped, scrubbed and swabbed with alcohol and Zephiran.

One approach was through an incision in the left flank. Paravertebral anaesthesia was combined with light general anaesthesia, and the bull was placed in right lateral recumbency.

A simpler approach was suggested by Dr D. D. Delahanty (personal communication). Epidural anaesthesia was used, and the operation was performed with the bull standing. A purse-string suture was used to close the anus. A semicircular incision was begun $\frac{1}{4}$ inch lateral to the hair line opposite the upper quadrant of the anus and extended ventrally to a point opposite the contralateral lower quadrant of the anus. The seminal vesicles were reached by blunt dissection, and their peritoneal investment was stripped away. The vesicles were severed close to the pelvic urethra using an equine ovariectomy knife. One bull (3027) failed to deliver spermatozoa after surgery, indicating that the vasa deferentia were occluded.

\section{Seminal biochemistry}

Hydrogen ion activity was measured with a Beckman $\mathrm{pH}$ meter using a singledrop hydrogen electrode. The colorimetric method of Roe (1934), as adapted by Mann (1948), was used to determine fructose concentration. Citric acid determination was based on the method of Speck, Moulder \& Evans (1946).

Seminal amino acid levels were determined by the procedure of Hopwood \& Gassner (1962). Alkaline phosphatase was measured according to the method of Bessey, Lowery \& Brock (1946).

Sodium and potassium were determined with a Beckman flame photometer coupled to a Beckman DU spectrophotometer. Chloride was measured by the method of Schales \& Schales (1941). Glycerylphosphorylcholine (GPC) was analysed according to the method of White (1959). Total nitrogen was determined by the method of Folin \& Wu (1919), as modified by Natelson (1963). The significance of differences between mean values was tested using Student's $t$-test (Steel \& Torrie, 1960).

\section{RESULTS}

\section{Pre-sperm fraction}

Mean values for biochemical components of the pre-sperm fraction before and after seminal vesiculectomy are shown in Table 1 . There was no change in $\mathrm{pH}$ as a result of vesiculectomy. Fructose, citric acid and potassium were reduced, while the concentration of sodium increased. There was little alkaline phosphatase activity before or after vesiculectomy, but vesiculectomy reduced 


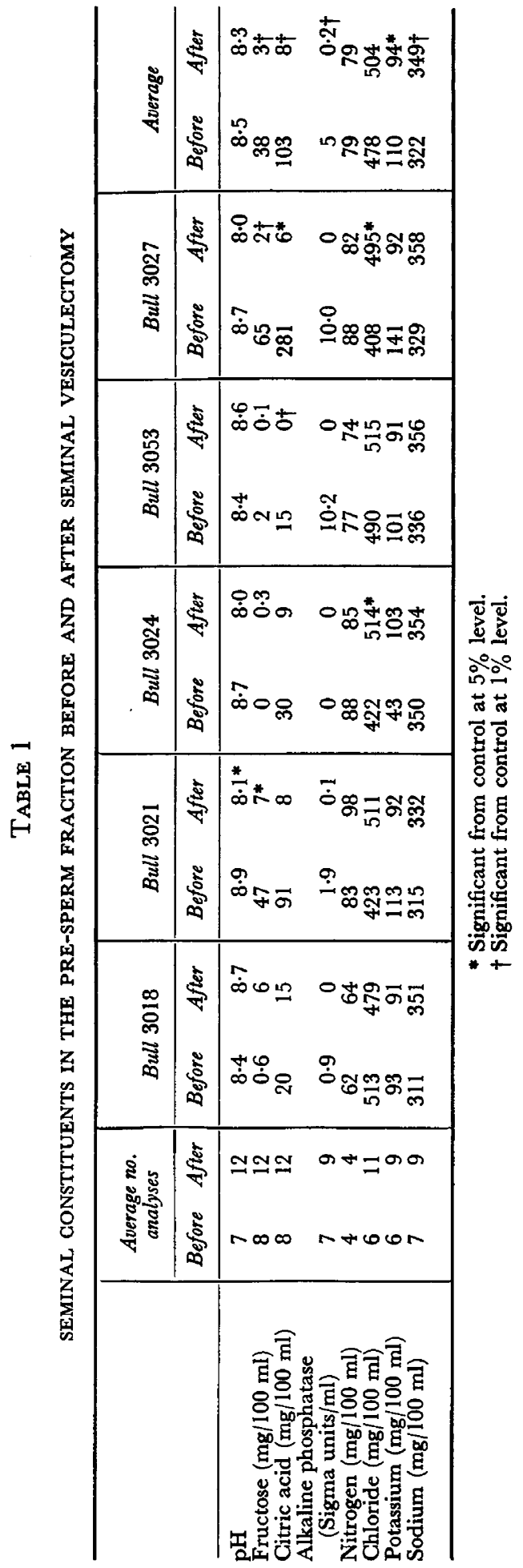


the low level of activity existing before surgery. Nitrogen and chloride levels were unaltered.

GPC was not detected in the pre-sperm fraction. Levels of free amino acids in the pre-sperm fraction have not previously been documented. The levels in $\mathrm{mg} / 100 \mathrm{ml}$, which were unaltered after vesiculectomy, were as follows: aspartic acid $0 \cdot 3 \pm 0 \cdot 2$, glutamic acid $3 \cdot 7 \pm 3 \cdot 0$, serine $0 \cdot 3 \pm 0 \cdot 3$, glycine $0.5 \pm 0.5$ and alanine $0 \cdot 6 \pm 0 \cdot 5$.

\section{Sperm-rich fraction}

Results of biochemical analysis of the sperm-rich fraction before and after vesiculectomy are shown in Table 2. The $\mathrm{pH}$ was not affected by seminal vesiculectomy. Differences in volume and the levels of fructose, citric acid, chloride, potassium, GPC, nitrogen, free amino acids and alkaline phosphatase activity were significant. The concentration of sodium was unaltered.

\section{DISGUSSION}

The decreases in fructose and citric acid in the sperm-rich fraction were expected after seminal vesiculectomy, since the seminal vesicles are the main source of seminal fructose (Mann, 1946) and of citric acid (Schersten, 1929) in bulls. Residual quantities of these components in semen after vesiculectomy may be due to contributions from the ampullary glands (Mann, 1948) or to incomplete removal of seminal vesicle tissue. The $82 \%$ reduction in seminal fructose and $57 \%$ reduction in citric acid following vesiculectomy indicate a differential depletion of the major vesicular gland contributions and support the evidence that other accessory glands, in addition to the seminal vesicles, contribute these factors. Decreases in fructose and citric acid in the pre-sperm fraction after vesiculectomy indicate that the seminal vesicles contribute to pre-sperm fluid.

Pre-sperm fractions were devoid of GPG before and after vesiculectomy, supporting the findings of Dawson, Mann \& White (1957) that GPG is secreted by the epididymis. Furthermore, GPC concentration increased in the spermrich fraction after vesiculectomy. We cannot explain, however, why GPC was present in high concentration in the ejaculate of bull 3027 after the vasa deferentia were presumably blocked.

Seminal vesiculectomy did not alter free amino acid levels in the pre-sperm fraction, but amino acids were increased in the sperm-rich fraction after vesiculectomy. Hess, Ludwick, Martig \& Ely (1960) found no significant increase in amino acids after ablation of seminal vesicles. Our results agree with the conclusion of Hopwood \& Gassner (1962) that the testes and epididymides are the major sources of seminal amino acids, because levels increased in the sperm-rich ejaculate after seminal vesiculectomy and markedly decreased when the vasa deferentia were occluded in bull 3027.

Decreased alkaline phosphatase activity in the sperm-rich fraction after seminal vesiculectomy and the low level of alkaline phosphatase in the presperm fluid, also decreased by vesiculectomy, further indicate that vesicular gland secretion is present in the pre-sperm fraction. 
Rothschild \& Barnes (1954) found an inverse relationship between sodium and potassium in seminal plasma, while calcium, chloride and nitrogen were positively correlated. Quinn, White \& Wirrick (1965) reported that the concentration of sodium in seminal vesicle fluid was almost twice that in epididymal semen. The concentration of potassium in vesicular gland fluid was about half that of epididymal semen. We found that sodium increased and potassium decreased in the pre-sperm fluid after vesiculectomy. We interpret this to mean that the high sodium content of the bulbo-urethral and prostate gland contributions to pre-sperm fluid was lowered by seminal vesicular secretion, which, richer in potassium, increased the level of this component in the pre-sperm fraction. Levels of sodium, chloride and potassium after vesiculectomy indicate that the bulbo-urethral and prostate glands contribute to the sperm-rich fraction, as proposed by Aalbers (1966). These secretions, high in sodium and chloride but low in potassium, apparently were capable of maintaining the sodium level, increasing chloride and decreasing potassium in the sperm-rich fraction after removal of the seminal vesicles.

Hess et al. (1960) found that the $\mathrm{pH}$ of pooled, successive ejaculates increased after seminal vesiculectomy. There was no change in the $\mathrm{pH}$ of pre-sperm or sperm-rich fractions as a result of vesiculectomy in our investigation. Aalbers (1966) reported that the contribution from the 'urethral glands', relative to the epididymal contribution, increased in the third through to the sixth successive ejaculates. In our study only a single, sperm-rich ejaculate was analysed which may account for the discrepancy.

\section{ACKNOWLEDGMENTS}

This work was supported by United States Public Health Service Grant GM 07120 from the National Institute of General Medical Sciences and by Colorado State Experiment Station Project 57. Published as Colorado State University Scientific Series No. 1179. Support of the senior author by the Agency for International Development is gratefully acknowledged.

\section{REFERENCES}

Aalbers, J. G. (1966) The contribution of the epididymis and the main accessory glands to ejaculates of bull semen. Int. F. Fert. 11, 7 .

BEsSEY, O. A., LOWERY, O. H. \& BROCK, M. J. (1946) A method for the rapid determination of alkaline phosphatase with five cubic millimeters of semen. F. biol. Chem. 164, 321.

Dawson, R. M. G., Mann, T. \& White, I. G. (1957) Glycerylphosphorylcholine and phosphorylcholine in semen and their relation to choline. Biochem. 7. 65, 627.

Faulkner, L. C., Masken, J. F. \& Hopwood, M. L. (1964) Fractionation of the bovine ejaculate. 7. Dairy Sci. 47, 823.

Folin, O. \& WU, H. (1919) A system of blood analysis. 7. biol. Chem. 38, 81.

Hess, E. A., Ludwick, T. M., Martig, R. C. \& Ely, F. (1960) Influence of seminal vesiculectomy on certain physical and biochemical properties of bovine semen. 7. Dairy Sci. 43, 256.

Hopwood, M. L. \& Gassner, F. X. (1962) The free amino acids of bovine semen. Fert. Steril. 13, 290.

MANN, T. (1946) Fructose, a constituent of semen. Nature, Lond. 157, 79.

Mann, T. (1948) Fructose content and fructolysis in semen. Practical application in the evaluation of semen quality. F. agric. Sci., Camb. 38, 323.

Natelson, S. (1963) Microtechniques of clinical chemistry, 2nd edn, p. 304. Thomas, Springfield, Illinois.

Quinn, P. J., White, Y. G. \& WirRICK, B. R. (1965) Studies of the distribution of the major cations in semen and male accessory secretions. J. Reprod. Fert. 10, 379. 
Roz, J. H. (1934) A colorimetric method for the determination of fructose in blood and urine. F. biol. Chem. 107, 15.

Rothschild, LORD \& BARNEs, H. (1954) Constituents of bull seminal plasma. F. exp. Biol. 31, 561.

Schales, O. \& Schales, S. S. (1941) A simple accurate method for the determination of chlorides in biological fluids. F. biol. Chem. 140, 879 .

Schersten, B. (1929) Occurrence of citric acid in the secretions of sex glands. Skand. Arch. Physiol. 58, 90.

Speck, J. F., Moulder, J. W. \& Evans, E. A., Jr. (1946) The biochemistry of the malaria parasite. V. Mechanism of pyruvate oxidation in the malaria parasite. 7 . biol. Chem. 164, 119.

Steel, R. G. D. \& Torrie, J. H. (1960) Principles and procedures of statistics, p. 43. McGraw-Hill, New York.

WHrte, I. G. (1959) Studies on the estimation of glycerol, fructose and lactic acid with particular reference to semen. Aust. F. exp. Biol. med. Sci. 37, 441. 